\title{
FORMULATION OF DESIGN TASKS OF TOWED UNDERWATER VEHICLES CREATION FOR SHALLOW WATER AND AUTOMATION OF THEIR MOTION CONTROL
}

\author{
Oleksandr Blintsov \\ Department of Computer Technologies and Information Security \\ Admiral Makarov National University of Shipbuilding \\ 9 Heroiv Ukrainy ave., Mykolaiv, Ukraine, 54025 \\ alex_blintsov@ukr.net \\ Volodymyr Sokolov \\ Chief Engineer - First Deputy General Director \\ State Enterprise «Production Association «O. M. Makarov Southern Machinebuilding Plant» \\ 1 Kryvorizka str., Dnipro, Ukraine, 49047 \\ sokolow@yuzhmash.com \\ Pavel Kucenko \\ Research Department \\ Admiral Makarov National University of Shipbuilding \\ 9 Heroiv Ukrainy ave., Mykolaiv, Ukraine, 54025 \\ arcadia.blacksea@gmail.com
}

\begin{abstract}
The towed underwater system is one of the fixed assets of the study of water areas. The effectiveness of its application depends on the characteristics laid at the design stage. The main task of the towed underwater vehicle (TUV) is the motion of technological equipment. Therefore, it is important to ensure the specified dynamic properties of the unit and automate the control of its motion. In the paper the typical forms of the unit are analyzed, the features of their control at small depths are set.

TUV control is carried out in conditions of uncertainty. Therefore, the design of an automatic control system (ACS) for its motion is proposed to be carried out using the appropriate synthesis method - the method of minimizing local functionals.

The control law contains integral components and, under the constraints of control actions, generates the problem of integral saturation. To eliminate the integral saturation in the work, the condition integration method is improved. On its basis, the control law and the structure of the controller of high dynamic accuracy of a second-order nonlinear object are synthesized. It is the basis for the synthesis of ACS controlled degrees of freedom of the underwater vehicle in conditions of uncertainty.

Usually TUVs contain two degrees of mobility. Translational motions of the unit are generated by changing its angular orientation. The paper synthesizes TUV controllers of pitch and roll based on the control law of the second order. Each control signal of the unit can affect both the roll and the pitch of the unit, which leads to decrease in the quality of control in general. To coordinate the work of controllers, a method is proposed, which is based on adjusting the initial conditions of the controller with greater error. On its basis, the automatic control system of the rotational motion of the unit is synthesized. It provides high dynamic precision control of two-dimensional rotational motion of the unit in uncertainty and is the basis for the ACS synthesis of its translational motion in space.
\end{abstract}

Keywords: towed underwater vehicle, automatic control system, rotational motion, integral saturation.

\section{Introduction}

Towed underwater systems (TUS) are among the most common types of underwater technology and are widely used for research and development of the oceans [1]. Currently, they are increasingly being used to carry out research and production work in shallow waters - on rivers and lakes, in coastal marine waters with depths of 30-50 meters [2].

Typical types of work in shallow water are [3-6]:

- hydrological and environmental studies;

- search and documentation of sunken objects; 
- survey work and mapping of the bottom surface of navigable waters;

- underwater archaeological research;

- humanitarian demining of the water area;

- work in the interests of the marine mining industry (search and survey of phyllophora fields, places of industrial fish and shellfish, etc.).

The main instruments of the unit for performing the above works are photo and video cameras, side-scan sonars, hydroacoustic profilographs, sensors of hydrophysical and hydrochemical characteristics of water, etc.

The structure of a typical TUS contains a cable winch (CW), which is located on the tugboat (TB), cable-tug (CT), towed underwater vehicle (TUV) and the launch system (LS). CT root end is fixed on the CW, CT suspension end is fixed on TUV (Fig. 1) [7].

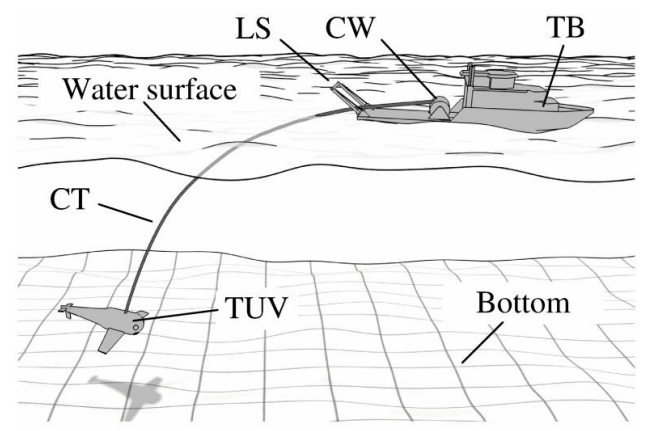

Fig. 1. The main elements of the towed underwater system

The features of the TUV use in shallow water include:

- high requirements for TUV mass-dimensional characteristics, due to the use of small TBs;

- high demands on the accuracy of the TUV spatial motion, due to the limitations of the vertical maneuver due to the small depths of water areas.

This makes the actual task of creating TUS for operation in shallow water areas and the synthesis of high-precision automatic control systems for the spatial motion of their TUVs.

\section{Literature review and problem statement}

Designing TUS as a maritime mobile object with a high level of automation is a well-known scientific problem [7]. From the standpoint of hydrodynamics and the theory of automatic control, TUS is an essentially nonlinear object, because it contains elements with concentrated (TB and TUV) and distributed (CT) parameters. These elements mechanically interact with each other and work in conditions of uncertainty.

A large number of scientific publications are devoted to research and design of TUS and their control systems.

The main problems that are solved in them include questions:

- calculation of the forces and moments arising at TUV and CT;

- mathematical modeling of the CT steady-state motion and its dynamics in transient modes;

- stabilization of the TUV motion on individual axes under the influence of external disturbances.

Thus, in [8], the general issues of designing and constructing a two-unit TUS are considered. The method of simulation modeling explores their dynamics and control methods using the PID controller. Sea rolling, towing speed and the position of the center of mass of the unit are taken into account.

The work [9] discusses monitoring and control of the towed force for safe TUV operation, methods of measuring and monitoring the towed force, and experimental methodology for obtaining the range of the towed force.

TUV hydrodynamic model is studied in [10]. The authors propose a new method of calculating the ideal towed system based on the calculation of Euler angles and determining the tension force at the CT end point. 
In work [11], a three-dimensional dynamic model of a typical TUS is investigated during its operation at a fixed depth of $2.5 \mathrm{~m}$. The features of the control unit in recirculation mode are established.

A three-dimensional hydrodynamic TUS model and a program for its calculation by various numerical methods are presented in [12]. The main advantage of the program is the use of an implicit method of integrating a system of differential equations, which ensures the stability of calculations of long-term transients.

The paper [13] is devoted to the comparison of mathematical models of the TUV CT stationary configuration with their experimental studies. A continuous and discrete 2D model of a stationary towing problem in a vertical plane at various towing speeds is considered. The advantages of using a CT discrete mathematical model are shown.

A new high-performance method for mathematical modeling of CT dynamic modes is described in [14]. The method provides high computational efficiency regardless of the degree of freedom of the TUS.

In [15], the TUV control system based on the state and feedback controllers using observers is investigated. The advantages of controllers based on the concept of observers with a high gain, compared with the use of controllers with a linear gain Kalman filter are shown.

These publications mainly deal with the study of the CT impact on the steady-state motion and the TUV dynamics, as well as questions of stabilizing the TUV motion in depth.

The issues of selecting the TUV hydrodynamic form and the synthesis of automatic control systems in scientific publications are not sufficiently covered.

\section{The aim and objectives of research}

The aim of research is analysis of the TUV hydrodynamic forms and the synthesis of a two-dimensional automatic control system of the rotational motion to ensure high dynamic accuracy of control of a typical TUV at shallow depths in conditions of uncertainty.

To achieve the goal it is proposed to solve the following objectives:

- perform analysis of the TUV features as a control object;

- improve the method of elimination of integral saturation for the ACS synthesis with limitations of control signals;

- synthesize the law of control of high dynamic accuracy of a non-linear object of the second order;

- synthesize controllers of TUV roll and pitch;

- synthesize the ACS with a TUV two-dimensional rotational motion.

\section{Research results}

\section{1. Features of TUV rotational and translational motions control}

The majority of the TUV is a cylindrical body, elongated in the direction of motion, with a streamlined shape with bearing surfaces (wings) and with tail feathers - a system of vertical and horizontal rudders and stabilizers [2]. For effective work of stabilizers, the center of mass of the TUV during the design is shifted to the maximum forward, and the tail part is designed from light materials and lengthened.

Two other hydrodynamic TUV forms, "flying wing" and "frame", are much less commonly used. To control the motion of the front armor of the first form, traditional wings are deepened from the elevons, and the second form is deepened wings and tail rudders.

The towed underwater vehicles used to study the bottom and underwater objects at shallow depths (up to $50 \mathrm{~m}$ ) have their own characteristics. Working conditions are characterized by the commensurability of the hydrodynamic forces arising on the CT with the hydrodynamic forces on the TUV body. This must be taken into account when designing its bearing surfaces and tail assembly, as well as their actuating actuators. In addition, due to the small CT length, external disturbances from the rolling of the TB direction are transmitted to the TUV body, which significantly impairs the quality of work of its main devices (sonars, photo and video equipment). This requires the development of high-precision automatic control systems for TUV depth, roll and pitch. 
"Planer-2" project TUV is considered $[16,17]$. Its body has a cylindrical shape with streamlined ends and is equipped with bearing surfaces (BS) and tail feathers in the form of control wings $(\mathrm{CW})$. BSs are arranged so that the resultant forces that it creates, compensate for the vertical component of the disturbing force from the CT. CWs are located in the aft part of the TUV, which makes it possible to create controllable differentiate and roll moments. The control action for the "Planer-2" project TUV is a vector-row $\overline{\mathrm{u}}$ :

$$
\overline{\mathrm{u}}=\left\{\mathrm{u}_{\text {left }}, \mathrm{u}_{\text {right }}\right\} ; \mathrm{u}_{\text {left }} \in[-1,1] ; \mathrm{u}_{\text {right }} \in[-1,1],
$$

where $\mathrm{u}_{\text {left }}-$ the control signal for the left control wing; $\mathrm{u}_{\text {right }}-$ the control signal of the right control wing.

At the same time, when $\mathrm{u}_{\text {left }}=\mathrm{u}_{\text {right }}$, TUV roll is zero and only the TUV depth controlled is controlled by changing the TUV pitch. The latter, in this case, is guided by a synchronous change of control actions for the left and right wings. If $\mathrm{u}_{\text {left }} \neq \mathrm{u}_{\text {right }}$, then there will be a roll and TUV shift to the side. Thus, the control of rotating degrees of freedom (roll and pitch) is the basis for controlling the translational degrees of freedom (vertical and lateral motion) of the TUV.

For turning each $\mathrm{CW}$, an automated electric drive is used, which is modeled using a first-order intensity setter:

$$
\begin{gathered}
\dot{\mathrm{u}}_{\text {out }}=\mathrm{T}_{\mathrm{int}}^{-1} \mathrm{sat}\left(\varepsilon, \varepsilon_{\mathrm{s}}\right) ; \\
\varepsilon=\mathrm{u}_{\mathrm{in}}-\mathrm{u}_{\text {out }} ; \operatorname{sat}\left(\varepsilon, \varepsilon_{\mathrm{s}}\right)=\left\{\begin{array}{l}
\varepsilon_{\mathrm{s}}, \text { at } \varepsilon>\varepsilon_{\mathrm{s}} ; \\
-\varepsilon_{\mathrm{s}}, \text { at } \varepsilon<-\varepsilon_{\mathrm{s}} ; \\
\varepsilon, \text { otherwise; }
\end{array}\right. \\
\alpha_{\text {left, right }}=\mathrm{Ku}_{\text {out(left), out(right) }} ; \mathrm{T}_{\text {int }}=0,01 \mathrm{~s} ; \varepsilon_{\mathrm{s}}=0,08 ; \mathrm{K}=-15^{\circ},
\end{gathered}
$$

where $u_{\text {in }}-$ the intensity setter input, $u_{\text {out }}$ - the intensity setter output, the dot indicates the time derivative; $\varepsilon$ - the error signal of the parameters $u_{\text {in }}$ and $u_{\text {out }} ; \varepsilon_{\mathrm{s}}$ - the parameter that determines the saturation threshold of the error signal $\varepsilon ; \mathrm{T}_{\text {int }}$ - the time constant, which determines the dynamics of the transition process when the parameter $\varepsilon$ leaves the saturation mode; $\operatorname{sat}\left(\varepsilon, \varepsilon_{\mathrm{s}}\right)-$ a function that implements a nonlinear element with a characteristic of the "saturation" type; $\alpha_{\text {left, right }}$ - respectively, the angles of rotation of the left and right $\mathrm{CW}$ relative to the TUV body; $\mathrm{K}$ - the scaling factor of the control action, since the parameters $\mathrm{u}_{\text {left, right }}$ are dimensionless, then the coefficient $\mathrm{K}$ has an angular dimension; $u_{\text {out(left), out(right) }}-$ the outputs of intensity controls, respectively, for the left and right CWs.

For negative values of $\mathrm{u}_{\text {left, right }}$ the angles of rotation of the left $\alpha_{\text {left }}$ and right $\alpha_{\text {right }}$ control wings have positive values, create a pitch on the TUV nose and make it go deeper. Accordingly, at positive values of the TUV control actions, the pitch will be received at the stern and will float. The choice of the negative sign of the coefficient $\mathrm{K}$ is made taking into account the fact that the final controlled parameter is the TUV translational motion along the vertical axis of the base coordinate system directed upwards [18]. Therefore, the signs of control actions (with the equality of their absolute values) correspond to the direction of TUV motion along the vertical axis of the base coordinate system.

If $u_{\text {left }}>u_{\text {right }}$, then $\alpha_{\text {left }}<\alpha_{\text {right }}$, in connection with this TUV get a roll on the left side. This, accordingly, will cause it to move to the right, and vice versa, if $u_{\text {left }}<u_{\text {right }}$, then $\alpha_{\text {left }}>\alpha_{\text {right }}$, in connection with this, TUV will receive a roll on the starboard. This, accordingly, will cause it to move to the left. Such motions are explained by the fact that the "lifting force" of the bearing surface is directed downwards.

Automation of TUV rotational motion control is the basis for automating the control of its translational motion.

\section{2. Synthesis of TUV pitch control law}

Transients in the CWs are much faster for transients when TUV rotational motion, so let's assume that the dynamics of the TUV rotational motion is subject to the second order of differential equations [16]. 
As a control object, TUV is a non-linear object that operates under uncertainty. Therefore, to synthesize the control law, let's use a method based on the concept of inverse dynamics together with minimization of local functionals [19].

When controlling a one-dimensional second-order object, the functional G(u), which is the normalized energy of the second derivative of the controlled variable, is subject to minimization [19]:

$$
G(u)=\frac{1}{2}\left[\ddot{y}_{d}\left(y_{g}, t\right)-\ddot{y}(t, u)\right]^{2}, t \geq 0,
$$

where $y$ - the controlled variable; $y_{d}$ - the desired value of the controlled variable obtained from the ACS reference model; $y_{\mathrm{g}}$ - specified value of the controlled variable (control problem); $\mathrm{u}$ - control signal (control action); $\mathrm{t}$ - time. Dots denote time derivatives.

The control action is obtained by minimizing the functional $\mathrm{G}(\mathrm{u})$ using the second order gradient search method [19]:

$$
\ddot{\mathrm{u}}+\mathrm{h} \dot{\mathrm{u}}=-\lambda \frac{\partial \mathrm{G}(\mathrm{u})}{\partial \mathrm{u}} ; \mathrm{h}, \lambda=\mathrm{const}>0 \text {, }
$$

where $\mathrm{h}$ and $\lambda$ - the parameters of the gradient search.

The partial derivative of the functional G(u) with respect to the variable $u$ is determined on the basis that the parameter $u$ directly affects only the highest derivative of the controlled parameter y:

$$
\frac{\partial G(u)}{\partial u}=-\left(\ddot{y}_{d}-\ddot{y}\right) \frac{\partial \ddot{y}}{\partial u} .
$$

Differential control law takes the following form:

$$
\ddot{u}+h \dot{u}=\sigma k\left(\ddot{y}_{d}-\ddot{y}\right) ; k>0 ; \quad \sigma=\operatorname{sign}\left(\frac{\partial \ddot{y}}{\partial u}\right),
$$

where $\mathrm{k}$ - the gain in the contour of the control function; $\operatorname{sign}(\cdot)$ - Signum function; $\sigma-$ a parameter that ensures the fulfillment of the sign rule [19].

To ensure high dynamic control accuracy, let's set the reference model in the following form:

$$
\begin{gathered}
\mathrm{T}_{\mathrm{r}}^{2} \ddot{\mathrm{e}}=\mathrm{Ke}_{\mathrm{g}}-2 \zeta_{\mathrm{r}} \mathrm{T}_{\mathrm{r}} \dot{\mathrm{e}}-\mathrm{e} ; \\
\mathrm{e}=\mathrm{y}_{\mathrm{g}}-\mathrm{y} ; \quad \mathrm{K}=1 ; \quad \zeta_{\mathrm{r}}=1 ; \quad \mathrm{e}_{\mathrm{g}}=0,
\end{gathered}
$$

where $\mathrm{e}$ - the control error, $\mathrm{e}_{\mathrm{g}}$ - the specified value of the control error; $\mathrm{y}_{\mathrm{g}}$ - the specified value of the controlled variable; $\mathrm{T}_{\mathrm{r}}$ - the time constant of the reference model, $\mathrm{K}$ - the gain of the reference model, $\zeta_{\mathrm{r}}$ - the damping coefficient of the reference model.

Let's single out from the reference model the highest derivative of the controlled parameter, which will be the desired acceleration of the controlled variable $\ddot{y}_{\mathrm{d}}$ :

$$
\ddot{y}_{\mathrm{d}}=\ddot{\mathrm{y}}_{\mathrm{g}}+\frac{2}{\mathrm{~T}_{\mathrm{r}}} \dot{\mathrm{e}}+\frac{1}{\mathrm{~T}_{\mathrm{r}}^{2}} \mathrm{e} .
$$

The parameter $\ddot{y}_{\mathrm{d}}$ is substituted into the control law equation (1).

To select the controller parameters $\mathrm{k}$ and $\mathrm{h}$, it is necessary to estimate the time constant of the control function loop. The speed of the control loop u must be significantly higher than the speed of the reference model [19]: 


$$
\frac{\mathrm{T}_{\mathrm{r}}}{\mathrm{T}_{\mathrm{u}}}=\mathrm{c}>>1,
$$

where $T_{u}$ - the time constant of the contour of the control function; $c$ - the parameter that determines the relationship between $\mathrm{T}_{\mathrm{r}}$ and $\mathrm{T}_{\mathrm{u}}$.

Based on the recommendations of [19], let's construct the differential equation of the contour of the control function:

$$
\left.\begin{array}{l}
\mathrm{T}_{\mathrm{u}}^{2} \ddot{\mathrm{u}}=\mathrm{u}_{\mathrm{opt}}-2 \zeta \mathrm{T}_{\mathrm{u}} \dot{\mathrm{u}}-\mathrm{u} ; \\
\mathrm{T}_{\mathrm{u}}^{2}=\frac{|\alpha|}{\mathrm{k}} ; 2 \zeta \mathrm{T}_{\mathrm{u}}=\frac{|\alpha| \mathrm{h}}{\mathrm{k}} ; \zeta=1 ; \alpha=\left(\frac{\partial \ddot{\mathrm{y}}}{\partial \mathrm{u}}\right)^{-1},
\end{array}\right\}
$$

where $\alpha$ - a parameter characterizing the inertia of the control object; $\zeta$ - the damping coefficient; $\mathrm{u}_{\mathrm{opt}}-\mathrm{a}$ control action that delivers the absolute minimum of the functional G(u). The sign of the parameter $\alpha$ corresponds to the sign of the parameter $\sigma$, so it declined and the absolute value of $\alpha$ remained in the equation.

If it is impossible to estimate the parameter $\alpha$ of the control object, then it is proposed to adjust the controller as follows. First, set the time constant of the reference model $\mathrm{T}_{\mathrm{r}}$ and the coefficient c. On the basis of them by combining expressions with the participation of $T_{u}$ with (2) determine the parameter $h$ :

$$
\mathrm{h}=2 \mathrm{~T}_{\mathrm{r}}^{-1} \mathrm{c} \text {. }
$$

Further increase the value of the parameter $k$ until the controller will not provide the desired dynamic characteristics of the ACS.

The control law in the form (1) permits a reduction of the order to $u$, that is, two orders of magnitude. Let's substitute $\ddot{y}_{d}$ in the control law and integrate it twice and obtain [20]

$$
\left.\begin{array}{l}
u=\sigma k\left(e+\frac{2}{T_{r}} e_{i}\right)+\chi_{i} ; \chi_{i}=\int_{0}^{t} \chi d t+C_{2} ; e=y_{g}-y ; \\
e_{i}=\int_{0}^{t} e d t+C_{1} ; \chi=\frac{\sigma k}{T_{r}^{2}} e_{i}-h u ; k>0 ; \sigma=\operatorname{sign}\left(\frac{\partial \ddot{y}}{\partial u}\right),
\end{array}\right\}
$$

where $\mathrm{C}_{1,2}$ - the integration constant, their value is usually taken to be zero.

The control law (3) makes it possible to ensure a high dynamic accuracy of controlling a second-order nonlinear object under uncertainty conditions without using information about derivatives of a controlled quantity.

\section{3. Improvement of the method of eliminating integral saturation and controller syn- thesis for controlling a second-order object}

When controlling real objects, the ACS should take into account the constraints of control actions that lead to integral saturation and a decrease in the quality of control. A well-known method for eliminating integral saturation is the integration method according to the condition [21], which provides for the termination of integration when the control action is out of allowable limits. After the control action enters the allowable range, the integration will continue from the value that was before the moment of entering the saturation.

With a step change in the control task $\mathrm{y}_{\mathrm{g}}$ or with its rapid increase, an overshoot is observed, due to the following. When the ACS is in the saturation zone, the law of control can produce the value of an unlimited control action $\hat{\mathrm{u}}$ that is much higher than the limit values: $|\hat{\mathrm{u}}|>>1$. For large $\mathrm{k}$ integrators go out of saturation as $\mathrm{y}$ approaches $\mathrm{y}_{\mathrm{g}}$, that is, for small |e|. Not having had time to work out the minimization of the functional G(u), the ACS again enters the saturation zone. 
It is proposed to improve the ACS performance by adjusting the initial integration conditions after the ACS has entered the saturation zone. Let's adjust the initial condition of the integrator for the parameter e. The value of the initial condition will be formulated so that when a controller $\hat{\mathrm{u}}$ drops into the saturation zone, the controller transfers it to the edge of this zone. Since the value of $\chi_{1}$ depends on $e_{i}$, and the value of $e_{i}$ will be changed artificially, the value of $\chi_{1}$ obtained by integration loses its meaning. Therefore, the initial condition of the integrator for the parameter $\chi_{1}$ is set equal to zero. The expression for the initial condition of the parameter $e_{i}$ is obtained on the basis of the control law:

$$
\mathrm{e}_{\mathrm{iIC}}=\frac{\mathrm{T}_{\mathrm{r}}}{2 \sigma \mathrm{k}}\left(\operatorname{sign}(\hat{\mathrm{u}})-\sigma \mathrm{ke}-\chi_{\mathrm{iIC}}\right) ; \chi_{\mathrm{iIC}}=0
$$

where $\chi_{\text {iIC }}-$ the initial condition of the integrator for the parameter $\chi_{i}$.

At the next iteration of the calculation of the control action, the equation for the control action as the value of $e_{i}$ will only get the calculated value of $e_{i \mathrm{iC}}$ and the resulting value $\hat{\mathrm{u}}$ will fall into the vicinity of the saturation limit.

Resetting the integrator of the parameter $e_{i}$ to the value of $e_{i I C}$ will allow the ACS to leave the saturation zone faster and work out the minimization of the functional G(u), thereby improving the quality of the ACS operation.

The effect of high-frequency switching control is observed when the computer implementation of the control law (3) with the adjustment of the initial conditions. It is due to the fact that resetting the integrator of the parameter $e_{i}$ to the value of $e_{i I C}$ causes the ACS to operate at the saturation limit. The amplitude of such a switch can be either imperceptible or reach large values depending on the parameters of the object, the controller and the integration step. To reduce this effect, it is proposed to expand the zone $\hat{\mathrm{u}}$ when determining signs of saturation $\mathrm{s}$. In addition, in order to avoid incorrect values of $u$ in the saturation mode, it is proposed to replace sign( $\hat{u})$ with sign(e).

The control law, taking into account the constraints of the control action and with the adjustment of the initial conditions of integration, takes the following form:

$$
\begin{aligned}
& \mathrm{u}(\hat{\mathrm{u}})=\left\{\begin{array}{l}
\hat{\mathrm{u}}, \text { at } \hat{\mathrm{u}} \in[-1,1] ; \\
\operatorname{sign}(\mathrm{e}), \text { otherwise, }
\end{array}\right. \\
& \mathrm{s}(\hat{\mathrm{u}})=\left\{\begin{array}{l}
\text { false, at } \hat{\mathrm{u}} \in\left[-\mathrm{K}_{\mathrm{s}}, \mathrm{K}_{\mathrm{s}}\right] ; \\
\text { true, otherwise; }
\end{array}\right. \\
& \hat{\mathrm{u}}:=\sigma \mathrm{k}\left(\mathrm{e}+\frac{2}{\mathrm{~T}_{\mathrm{r}}} \mathrm{e}_{\mathrm{i}}\right)+\mathrm{X}(\chi, \mathrm{s}, 0, \mathrm{t}) ; \\
& \mathrm{e}_{\mathrm{i}}:=\mathrm{X}\left(\mathrm{e}, \mathrm{s}, \mathrm{e}_{\mathrm{iIC}}, \mathrm{t}\right) ; \chi=\frac{\sigma \mathrm{k}}{\mathrm{T}_{\mathrm{r}}^{2}} \mathrm{e}_{\mathrm{i}}-\mathrm{hu} ; \\
& \mathrm{e}_{\mathrm{iIC}}=\frac{\mathrm{T}_{\mathrm{r}}}{2 \sigma \mathrm{k}}\left[\mathrm{K}_{\mathrm{s}} \operatorname{sign}(\mathrm{e})-\sigma \mathrm{ke}-\mathrm{X}(\chi, \mathrm{s}, 0, \mathrm{t})\right] ; \\
& \mathrm{k}>0 ; \quad \sigma=\operatorname{sign}\left(\frac{\partial \ddot{y}}{\partial \mathrm{u}}\right) ; \mathrm{K}_{\mathrm{s}} \geq 1,
\end{aligned}
$$

where $\mathrm{K}_{\mathrm{s}}$ - the coefficient of expansion of the zone of allowable values $\hat{\mathrm{u}} ; \mathrm{X}(\cdot)$ - the integrator model, the integrand is specified as the first argument, the sign of saturation is given as the second argument, the initial condition of integration is entered as the third argument, and time is the fourth argument.

The block diagram of the controller built on its basis is shown in Fig. 2.

The "Sat" block in the controller structure (Fig. 2) calculates the parameter s and the limited control action $\mathrm{u}$, which is applied to the object, based on its unlimited value $\hat{\mathrm{u}}$.

As a result of improving the method of eliminating integral saturation, a controller of high dynamic accuracy is obtained by a second-order object, able to work in conditions of uncertainty. 
The controller input receives the difference between the given $y_{g}$ and the actual $y$ values of the controlled parameter, that is, the control error e. The output is a control action u.

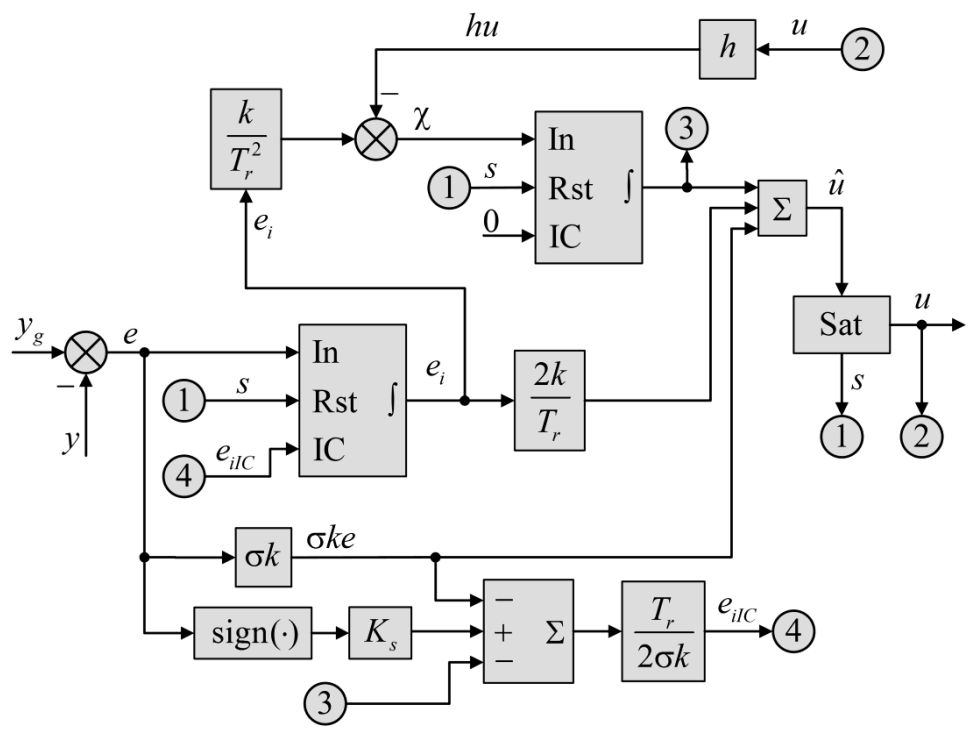

Fig. 2. Block diagram of the controller with the adjustment of the initial conditions

\section{4. Synthesis and investigation of the automatic control system of TUV rotational motion}

The synthesis of a multidimensional ACS by the TUV rotational motion provides for controller adjustments of the TUV roll and pitch and the coordination of their work.

Based on the results of simulation modeling, the controller parameters of the roll and pitch are selected (Table 1).

Table 1

Parameters of roll and pitch controllers

\begin{tabular}{ccc}
\hline Parameter & Roll controller & Pitch controller \\
\hline $\mathrm{T}_{\mathrm{r}} \mathrm{s}$ & 0,5 & 0,5 \\
$\mathrm{~s}$ & 5 & 5 \\
$\mathrm{k}, \mathrm{deg}^{-1}$ & 1 & 2 \\
$\mathrm{~h}, \mathrm{~s}^{-1}$ & 20 & 20 \\
$\sigma$ & 1 & 1,06 \\
$\mathrm{~K}_{\mathrm{s}}$ & 1,06 & $\mathrm{u}_{\psi}$ \\
$\mathrm{u}_{\text {left }}$ & $-\mathrm{u}_{\theta}$ & $\mathrm{u}_{\psi}$
\end{tabular}

In Table 1: $u_{\theta}-$ the output of the roll controller, $u_{\psi}-$ the output of the pitch controller.

Such a choice of parameters provides high dynamic control accuracy with a sinusoidal control task and a small overshoot with a step change in the control task. It was possible to reduce the overshoot due to the adjustment of the initial conditions of integration in the control process. Fig. 3, 4 show the ACS simulation results by the TUV pitch with a step change in the control task.

In Fig. 4, 5: $\psi_{\mathrm{g}}$ - the set value of the pitch, $\psi$-the actual value of the pitch (controlled quantity).

TUV depth was reduced to $19.5 \mathrm{~m}$ at $\psi>0$ (pitch at the stern) and increased to $20.5 \mathrm{~m}$ at $\psi<0$ (pitch to the bow). 

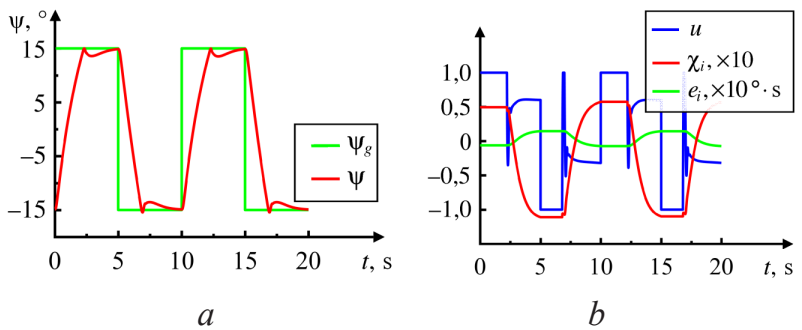

Fig. 3. ACS simulation results by the TUV pitch with an algorithmic prohibition of integration at a towing speed of $1 \mathrm{~m} / \mathrm{s}: a$ - control task and controlled parameter;

$b$ - control signal and the values of the integrated parameters
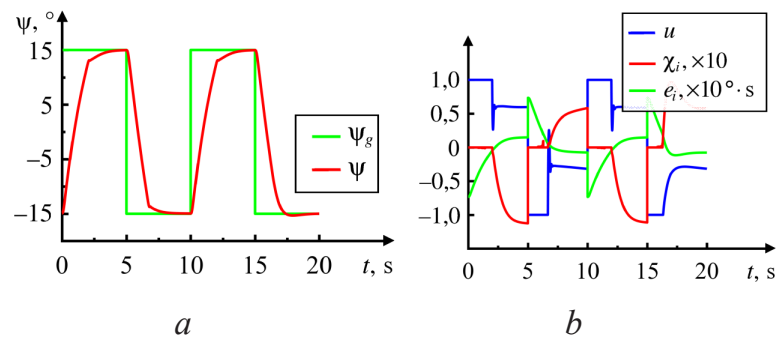

Fig. 4. ACS simulation results by TUV pitch with the adjustment of the initial conditions at a towing speed of $1 \mathrm{~m} / \mathrm{s}: a$ - control task and controlled parameter;

$b-$ control signal and the values of the integrated parameters

As it is possible to see, the use of an improved method for eliminating integral saturation (Fig. 4) provides a reduced overshoot compared to the classical method of integrating the condition (Fig. 3).

Fig. 5, 6 show the results of ACS simulation with the TUV roll with a harmonious change in the control task and various towing speeds.
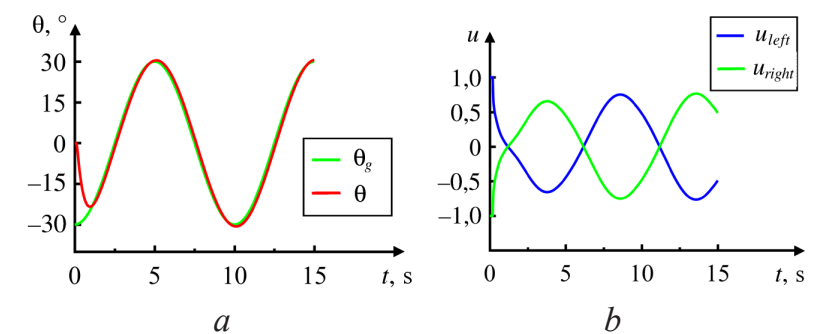

Fig. 5. ACS simulation results by TUV roll at a towing speed of $1 \mathrm{~m} / \mathrm{s}$ : $a$ - set and controlled values, $b-$ control actions
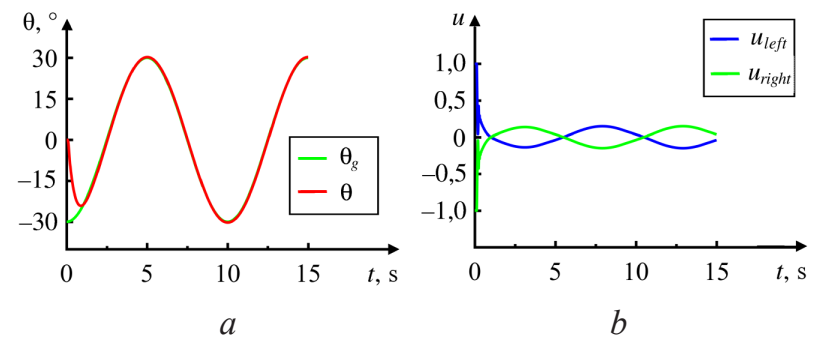

Fig. 6. ACS Simulation results by TUV roll at a towing speed of $3 \mathrm{~m} / \mathrm{s}$ : $a-$ set and controlled values, $b-$ control actions

In Fig. 5, 6: $\theta_{g}$ - the given value of the roll, $\theta$ - the actual value of the roll (controlled quantity). 
The control task changes in such a way that the ACS enters saturation only at the beginning of the simulation, when the control error is of great importance. Such parameters of the control task are selected in order to assess the controller accuracy.

The simulation results show a high dynamic accuracy of the controllers of the TUV angular orientation at different towing speeds (from 1 to $3 \mathrm{~m} / \mathrm{s}$ ) and various forms of the control task. But these results were obtained when controllers were working separately from each other.

For automatic control of the TUV multidimensional rotational motion it is necessary to coordinate the operation of the roll and pitch controllers. First of all, let's coordinate the outputs of the roll $\mathrm{u}_{\theta}$ and pitch controllers $\mathrm{u}_{\psi}$ :

$$
\mathrm{u}_{\text {left }}=\mathrm{u}_{\psi}-\mathrm{u}_{\theta} ; \mathrm{u}_{\mathrm{right}}=\mathrm{u}_{\psi}+\mathrm{u}_{\theta} \text {. }
$$

Each control wing can influence both the roll and the pitch of TUV. The main problem with the coordination of controlled actions is the saturation of control loops. For example, the control action $\mathrm{u}_{\text {left }}$ or $\mathrm{u}_{\text {right }}$ can get into saturation even if the outputs of the controllers $\mathrm{u}_{\theta}$ and $\mathrm{u}_{\psi}$ are within acceptable limits. This leads to deterioration in the control quality. The sign of saturation can be formed by the variables $u_{\text {left }}$ and $u_{\text {right }}$. But this will not improve the control quality, since the integrators of all control circuits are reset. This will lead to additional deviations of the controlled values from their specified values.

To coordinate the controller operation, a method is proposed, which is based on adjusting the initial conditions of the controller with greater error. Its essence is as follows. First, to determine the sign of ACS saturation with the TUV angular position $s$ on the basis of the outputs of the roll and pitch controllers:

$$
\mathrm{s}\left(\mathrm{u}_{\theta}, \mathrm{u}_{\psi}\right)=\left\{\begin{array}{l}
\text { true, at }\left|\mathrm{u}_{\psi}\right|+\left|\mathrm{u}_{\theta}\right|>1 \\
\text { false, otherwise. }
\end{array}\right.
$$

Let's note that the qualities $\mathrm{u}_{\theta}$ and $\mathrm{u}_{\psi}$ are taken to limit the outputs of the roll and pitch controllers.

Next, let's determine how much it is necessary to reduce the output of one of the controllers in order to derive the ACS from the saturation zone; let's denote this value by $\mathrm{u}_{\Delta}$ :

$$
\mathrm{u}_{\Delta}=\left|\mathrm{u}_{\psi}\right|+\left|\mathrm{u}_{\theta}\right|-1
$$

The main feature that will determine which of the controllers should be reset is the difference between roll control errors $\mathrm{e}_{\theta}$ and pitch $\mathrm{e}_{\psi}$. If the absolute value of the pitch error $\mathrm{e}_{\psi}$ exceeds the absolute value of the roll error $e_{\theta}$, then reset the pitch control integrators. If the absolute value of roll error $\mathrm{e}_{\theta}$ exceeds the absolute value of pitch error $\mathrm{e}_{\psi}$, then reset the roll controller integrators. If the errors are the same, then reset both controllers:

$$
\begin{aligned}
& \mathrm{s}_{\theta}\left(\mathrm{e}_{\psi}, \mathrm{e}_{\theta}, \mathrm{s}\right)=\left\{\begin{array}{l}
\text { true, at } \mathrm{s} \wedge\left|\mathrm{e}_{\psi}\right| \leq\left|\mathrm{e}_{\theta}\right| ; \\
\text { false, otherwise }
\end{array}\right. \\
& \mathrm{s}_{\psi}\left(\mathrm{e}_{\psi}, \mathrm{e}_{\theta}, \mathrm{s}\right)=\left\{\begin{array}{l}
\text { true, at } \mathrm{s} \wedge\left|\mathrm{e}_{\psi}\right| \geq\left|\mathrm{e}_{\theta}\right| ; \\
\text { false, otherwise }
\end{array}\right. \\
& \mathrm{e}_{\theta}=\theta_{\mathrm{g}}-\theta, \\
& \mathrm{e}_{\psi}=\psi_{\mathrm{g}}-\psi,
\end{aligned}
$$

where $s_{\theta, \psi}$ - the dump flags of integrators of roll and pitch controllers, respectively. 
The initial integration conditions after the reset also need to be adjusted to the fact that due to the output of which is removed from the ACS controllers from the saturation zone:

$$
\begin{aligned}
& \mathrm{u}_{\psi . \text { IC }}=\left\{\begin{array}{l}
\operatorname{sign}\left(\mathrm{u}_{\psi}\right)\left(\left|\mathrm{u}_{\psi}\right|-\mathrm{u}_{\Delta}\right), \text { at }\left|\mathrm{e}_{\psi}\right|>\left|\mathrm{e}_{\theta}\right| ; \\
\mathrm{u}_{\psi}, \text { at }\left|\mathrm{e}_{\psi}\right|<\left|\mathrm{e}_{\theta}\right| ; \\
\mathrm{u}_{\psi}^{\prime}, \text { at }\left|\mathrm{e}_{\psi}\right|=\left|\mathrm{e}_{\theta}\right| .
\end{array}\right. \\
& \mathrm{u}_{\theta . \mathrm{IC}}=\left\{\begin{array}{l}
\mathrm{u}_{\theta}, \text { at }\left|\mathrm{e}_{\psi}\right|>\left|\mathrm{e}_{\theta}\right| ; \\
\operatorname{sign}\left(\mathrm{u}_{\theta}\right)\left(\left|\mathrm{u}_{\theta}\right|-\mathrm{u}_{\Delta}\right), \text { at }\left|\mathrm{e}_{\psi}\right|<\left|\mathrm{e}_{\theta}\right| ; \\
\mathrm{u}_{\theta}^{\prime}, \text { at }\left|\mathrm{e}_{\psi}\right|=\left|\mathrm{e}_{\theta}\right| .
\end{array}\right.
\end{aligned}
$$

If the absolute values of the error control level than ASC is derived by the means of both controllers. In this case, it is also necessary that the controls $u_{\text {left }}$ and $u_{\text {right }}$ are within acceptable limits. For this, the normalization factor $\mathrm{k}_{\mathrm{u}}$ will be calculated:

$$
\mathrm{k}_{\mathrm{u}}=\left\{\begin{array}{l}
1, \text { at } \max \left(\left|\mathrm{u}_{\text {left }}\right|,\left|\mathrm{u}_{\text {right }}\right|\right)<1 \\
\max \left(\left|\mathrm{u}_{\text {left }}\right|,\left|\mathrm{u}_{\text {right }}\right|\right), \text { otherwise. }
\end{array}\right.
$$

Based on it, the parameters $\mathrm{u}_{\theta}^{\prime}$ and $\mathrm{u}_{\psi}^{\prime}$ are calculated:

$$
\mathrm{u}_{\psi}^{\prime}=\frac{\mathrm{u}_{\psi}}{\mathrm{k}_{\mathrm{u}}} ; \mathrm{u}_{\theta}^{\prime}=\frac{\mathrm{u}_{\theta}}{\mathrm{k}_{\mathrm{u}}} .
$$

Initial conditions will be determined similarly to (4):

$$
\mathrm{e}_{\theta, \psi \cdot \mathrm{iIC}}=\frac{\mathrm{T}_{\mathrm{r}}}{2 \sigma \mathrm{k}}\left(\mathrm{u}_{\theta, \psi \cdot \mathrm{IC}}-\sigma \mathrm{ke}_{\theta, \psi}\right) .
$$

The coefficient $K_{s}$ of the controllers should be chosen to be slightly less than one, so that after resetting the control loops that are not immediately saturated.

Thus, the ACS of TUV rotational motion consists of matched controllers of the TUV roll and pitch. These controllers are synthesized on the basis of the control law (5) and agreed upon on the basis of the proposed method for adjusting the initial conditions of the controller with greater error.

Let's perform simulation of synthesized ACS of TUV rotational motion. With a harmonious change of the control task, the ACS provides high dynamic control accuracy if it does not fall within the saturation zone.

Fig. 7 shows the ACS transient processes by TUV rotational motion in conditions of uncertainty.

The parameters of the control task are chosen so that after the completion of the transition process, one of the controlled variables starts the transition process on the other controlled quantity. This made it possible to assess the influence of the control circuits on each other.

As it is possible to see, when operating without coordination, transients for eliminating errors affect other control loops and cause a deterioration in quality (Fig. 7, a, c). And when using the ACS with the coordination of control actions based on the proposed method of adjusting the initial conditions, the quality of control almost does not deteriorate (Fig. 7, $\boldsymbol{b}, \boldsymbol{d}$ ).

The synthesized ACS provides high precision control of the TUV two-dimensional rotational motion in conditions of uncertainty. It is the basis for the synthesis of ACS of TUV transitional motion in space. 

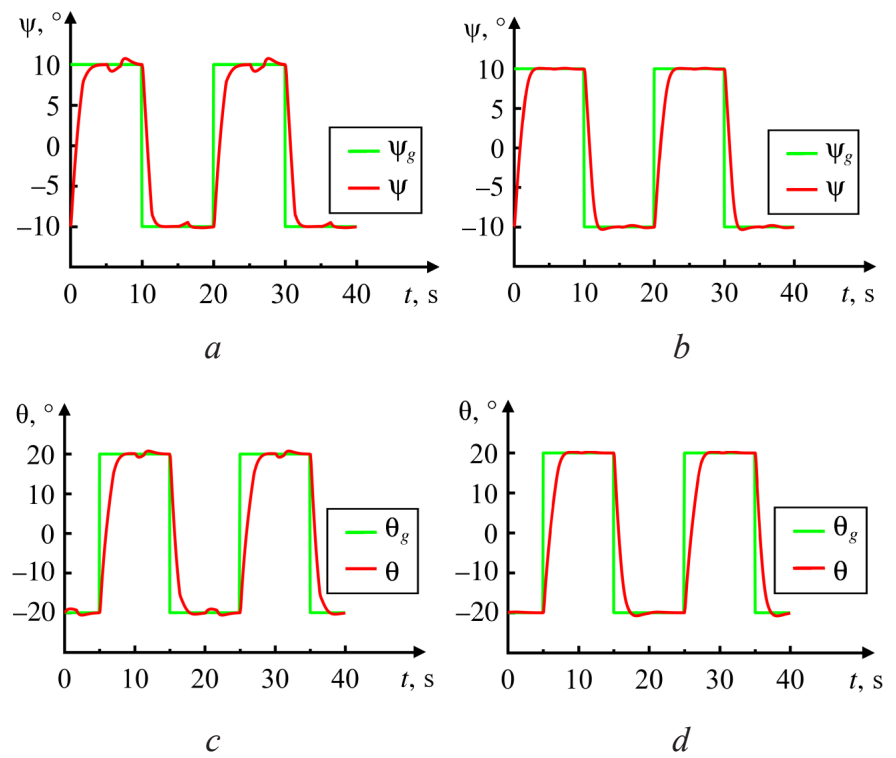

Fig. 7. ACS simulation results by the TUV rotational motion: $a-T U V$ pitch, ACS without matching; $b$ - TUV pitch, ACS with matching; $c$ - TUV roll, ACS without matching; $d-\mathrm{TUV}$ roll, ACS with matching

\section{Conclusions}

1. Based on the analysis of the most common hydrodynamic forms of towed underwater vehicles, features of controlling them at shallow depths for the synthesis of automatic control systems for their motion have been established.

2. The integration-by-condition method has been improved to eliminate the integral saturation of the automatic control system by forming the initial integration conditions so that when a control hits the saturation zone, the reset of the controller integrators will transfer it to the edge of this zone.

3. On the basis of the improved integration-by-condition method and the method of minimizing local functionals, the control law and the structure of the high dynamic precision controller have been synthesized for a second-order nonlinear object as the theoretical basis for the synthesis of automatic control systems for underwater vehicle controlled degrees of freedom in conditions of uncertainty.

4. Roll and pitch controllers of the towed underwater vehicle have been synthesized based on the second order control law and improved integration-by-condition method as the basis for the synthesis of a two-dimensional automatic control system of the towed underwater vehicle.

5. The automatic control system for the rotational motion of a towed underwater vehicle has been synthesized based on synthesized roll and pitch controllers and the proposed method for matching control circuits, which provides high dynamic accuracy of controlling the two-dimensional rotational motion of a towed underwater vehicle under conditions of uncertainty and is the basis for the synthesis of an automatic control system for its translational motion in space.

\section{References}

[1] Podvodnye tekhnologii i sredstva osvoeniya Mirovogo okeana (2011). Moscow: Oruzhie i tekhnologii, 779 .

[2] Rimskiy-Korsakov, N. A. (2017). Tekhnicheskie sredstva dlya issledovaniy dna akvatoriy gidrolokacionnymi metodami. Mezhdunarodniy zhurnal prikladnyh i fundamental'nyh issledovaniy, 10, 205-213.

[3] Blintsov, O. V., Nadtochiy, A. V. (2014). The generalized underwater technics efficiency estimation methodology of deep sea archaeological projects. Eastern-European Journal of Enterprise Technologies, 1 (3 (67)), 25-29. doi: https://doi.org/10.15587/1729-4061.2014.21045 
[4] Nadtoshy, A. (2016). Identification of risks in the course of managing the deep sea archeological projects using marine robotics. EUREKA: Physics and Engineering, 6, 59-64. doi: https:/doi.org/ 10.21303/2461-4262.2016.00244

[5] Blintsov, V., Hrytsaienko, M. (2016). Improvement of the management of material and technical resources of water cleaning projects from explosive objects. Technology Audit and Production Reserves, 6 (2 (32)), 51-56. doi: https://doi.org/10.15587/2312-8372.2016.86768

[6] Mohamed, H., Nadaoka, K., Nakamura, T. (2018). Assessment of Machine Learning Algorithms for Automatic Benthic Cover Monitoring and Mapping Using Towed Underwater Video Camera and High-Resolution Satellite Images. Remote Sensing, 10 (5), 773. doi: https://doi.org/10.3390/rs10050773

[7] Dudykevych, V., Oleksandr, B. (2016). Tasks statement for modern automatic control theory of underwater complexes with flexible tethers. EUREKA: Physics and Engineering, 5, 25-36. doi: https://oi.org/ $10.21303 / 2461-4262.2016 .00158$

[8] Linklater, A. (2005). Design and Simulation of a Towed Underwater Vehicle. Thesis submitted to the Faculty of the Virginia Polytechnic Institute and State University in partial fulfillment of the requirements for the degree of Master of Science In Aerospace Engineering. Blacksburg. Virginia, 170.

[9] Choi, J.-K., Shiraishi, T., Tanaka, T., Kondo, H. (2011). Safe operation of an autonomous underwater towed vehicle: Towed force monitoring and control. Automation in Construction, 20 (8), 1012-1019. doi: https://doi.org/10.1016/j.autcon.2011.04.002

[10] Feng, D. K., Zhao, W. W., Pei, W. B., Ma, Y. C. (2011). A New Method of Designing Underwater Towed System. Applied Mechanics and Materials, 66-68, 1251-1255. doi: https://doi.org/10.4028/www. scientific.net/amm.66-68.1251

[11] Chuanlong, L., Yuwen, Z., Xulong, Y. (2012). Simulation of Recycling Cable in Underwater Towed System. Proceedings of the 1st International Conference on Mechanical Engineering and Material Science. doi: https://doi.org/10.2991/mems.2012.38

[12] Srivastava, V. K., Tamsir, M. (2011). Dynamic behavior of underwater towed cable in linear profile. International Journal of Scientific \& Engineering Research, 2 (7). Available at: https://pdfs.semanticscholar.org/fe04/8af7057476a54f47dbd7c344e6b59d854fcf.pdf

[13] Paifelman, E. (2017). A comparison between mathematical models of stationary configuration of an underwater towed system with experimental validations for oceans'17 MTS/IEEE Aberdeen conferences. Conference: OCEANS 2017 - Aberdeen. doi: https://doi.org/10.1109/oceanse.2017.8084854

[14] Wang, G., Rong, B., Tao, L., Rui, X. (2012). Riccati Discrete Time Transfer Matrix Method for Dynamic Modeling and Simulation of an Underwater Towed System. Journal of Applied Mechanics, 79 (4), 041014. doi: https://doi.org/10.1115/1.4006237

[15] Minowa, A. (2015). System Analyses and motion Control of a Towed Underwater Vehicle. Master's Thesis. Graduate School of Marine Science and Technology. Tokyo University of Marine Science and Technology.

[16] Blintsov, O. V., Sokolov, V. V. (2017). Specialized simulating complex for studying motion dynamics of the towed underwater system. Collection of Scientific Publications NUS, 3. doi: https://doi.org/ 10.15589/jnn20170308

[17] Blintsov, O. V., Sokolov, V. V. (2018). Imitatsiyna model dynamiky prostorovoho rukhu bezekipazhnoi pidvodnoi buksyruvanoi systemy yak obiekta keruvannia. Innovatsiyi v sudnobuduvanni ta okeanotekhnitsi: mater. IX Mizhnar. nauk.-tekhn. konf., 328-330.

[18] Lukomskiy, Yu. A., Peshekhonov, V. G., Skorohodov, D. A. (2002). Navigaciya i upravlenie dvizheniem sudov. Sankt-Peterburg: Elmor, 360.

[19] Krut'ko, P. D. (2004). Obratnye zadachi dinamiki v teorii avtomaticheskogo upravleniya. Cikl lekciy. Moscow: Mashinostroenie, 576.

[20] Blintsov, O. V., Sokolov, V. V., Korytskyi, V. I. (2018). Avtomatychne keruvannia bezekipazhnym pidvodnym kompleksom systemy monitorynhu akvatoriyi v umovakh nevyznachenosti: mater. VIII Vseukr. nauk.-tekhn. konf. z mizhn. uchastiu. Suchasni problemy informatsiynoi bezpeky na transporti, 19-26.

[21] Denisenko, V. V. (2009). Komp'yuternoe upravlenie tekhnologicheskim processom, eksperimentom, oborudovaniem. Moscow: Goryachaya liniya - Telekom, 608. 